\title{
In-vitro antimicrobial and synergistic properties of water soluble green and black tea extracts
}

\author{
Stephen Karori Mbuthia ${ }^{1}$, Francis Nyamu Wachira ${ }^{2}$ and Robert Kipyegon Koech $^{3}$ \\ ${ }^{1}$ Department of Biochemistry and Molecular Biology, Egerton University, P.O. Box 536-20115, Egerton, Kenya. \\ ${ }^{2}$ Association for Strengthening Agricultural Research in East and Central Africa (ASARECA), P.O. Box 765, Entebbe, \\ Uganda. \\ ${ }^{3}$ Tea Research Foundation of Kenya (TRFK), P.O. Box 820-20200, Kericho, Kenya.
}

Received 23 January, 2014; Accepted 10 March, 2014

\begin{abstract}
Green and black teas extracts are known for their antibacterial activity against many pathogenic microorganisms. These studies have been necessitated by the need to combat the recent rise of drugresistant human pathogens which is becoming a common occurrence in the world making easily manageable infections to become life threatening illnesses. This study evaluated the antimicrobial activity of water soluble green and black tea extracts from a high quality Kenyan tea clone TRFK 6/8 against antibiotic resistant Escherichia coli ATCC 25922 and Staphylococcus aureusATCC 25923 using agar well diffusion method. Green and black tea extracts effectively inhibited the growth of both $E$. coli ATCC 25922 and S. aureus ATCC 25923 at concentrations of 0.1 and $0.05 \mathrm{mg} / \mathrm{ml}$, respectively after $24 \mathrm{~h}$. Green tea extracts and gentamicin showed greater zone of inhibition compared to penicillin $\mathbf{G}$. In addition, the possible synergistic activity of water soluble green tea extract and antibiotics was also determined using agar well diffusion method. A combination of penicillin $G$ and green tea extract inhibited the growth of E. coli ATCC 25922 and S. aureus ATCC 25923 compared to penicillin G alone while gentamicin exhibited an additive and antagonistic effect depending on tested bacteria. Green and black tea extracts can be used as an antimicrobial agent and also green tea extract can be used in combination with penicillin $G$ to manage resistant pathogenic bacteria. Furthermore, tea which is a proven safe, cheap and readily available compound can be used in more ambitious trials to test the antimicrobial efficacy and chemo-preventive effects in animal and human models.
\end{abstract}

Key words: Green tea, black tea, antimicrobial activity, synergistic activity, gentamicin, penicillin G.

\section{INTRODUCTION}

Tea which is the most widely consumed beverage in the world is manufactured from the tender leaves of the plant Camellia sinensis (Cabrera et al., 2003). The two types of tea products that are widely consumed are green and black tea. Green tea is widely consumed in China, the Middle East, while black tea is consumed in India,

${ }^{\star}$ Corresponding author. E-mail: karorism@gmail.com. Tel: +245-722 493572.

Author(s) agree that this article remain permanently open access under the terms of the Creative Commons Attribution License 4.0 International License 
European countries and regions of Africa (Obanda et al., 2001). The dried leaf of the evergreen tea bush Camellia sinensis from which tea is processed, contains a wide variety of biologically active compounds such as polyphenols, methylxanthines, essential oils, proteins, vitamins and amino acid (Bastos et al., 2006; Gallaher et al., 2006). However, most of tea biological activities are ascribed to the polyphenolic fraction, namely: tea catechins (Cabrera et al., 2003). The polyphenols present in tea include: epigallocatechingallate (EGCG), epicatechin (EC), epigallocatechin (EGC) and epicatechingallate (ECG) in green tea, while theaflavins (TFs) and thearubigins (TRs) are present in black tea. Of these polyphenolic components of tea, EGCG is the major constituent and is also the component with the highest bioactivity in green tea due to its high degree of hydroxylation and gallation (Lu et al., 2003). However, many studies have focused on the role of a single catechin EGCG in preventing diseases in human but it is important to point out that the overall protective effect of tea may require a combined action of several components in the beverage. Catechins which belong to the flavan-3-ols family of polyphenols have recently received considerable attention because of their potential therapeutic effects. Emerging scientific data from pharmacological and physiological studies continue to show that tea has beneficial effects on human health $\mathrm{Hu}$ et al., 2004; Vanessa and Williamson, 2004; Yamamoto et al., 2004). Considerable attention is currently being focused on the role of dietary and medicinal phytochemicals to inhibit, reverse or retard diseases mainly due to their radical scavenging properties. Since tea can be consumed over long periods of time without any known side effects, its possible role as an adjunct therapeutic agent in managing bacterial infections deserves consideration.

Recent reports have indicated antimicrobial properties of tea catechins on resistant bacteria and fungi (Hiroshi, 2012). Studies have reported that catechin from green tea inhibit Staphylocococcus aureus, Vibrio parahemolyticus, Clostidium perfringens, Bacillus cereus, Pleisomonas shigelloides, Aeromonas sobria, Acinetobacter baumannii and other food borne pathogens (Friedman et al., 2006; Hiroshi, 2012, Osterburg et al., 2012). Japanese green tea extracts have also been reported to inhibit the growth of Vibrio choleraeand Shigella dysentriae (Das, 1962). Theaflavins and thearubigins in black tea have also been shown to have antibacterial properties both in vivo and in vitro (Bandyopadhyayet et al., 2005). However limited research has been done on antimicrobial properties of Kenyan black tea and synergism of green tea extract in combination with some of conventional antibiotics. The purpose of this study was to establish whether black and green teas have antimicrobial activity and the level of synergistic or antagonistic effects of green tea extracts with antibiotics.

\section{MATERIALS AND METHODS}

\section{Bacteria}

The test bacteria of the American Type Culture Collection (ATCC) were obtained from the Department of Biochemistry, Egerton University (Njoro) and included Escherichia coli ATCC 25922 and Staphylococcus aureusATCC 25923.

\section{Tea samples}

The tea sample were sourced from the Tea Research Foundation of Kenya's Kangaita substation in Kirinyaga $\left(0^{\circ} 26^{\prime} \mathrm{S}\right.$ and $37^{\circ} 15^{\prime} \mathrm{E}$, elevation $2020 \mathrm{~m}$ a.m.s.I) and processed into green and black tea products at Tea Research Foundation of Kenya miniature factory in Kericho as described by Karori et al. (2007).

\section{Antimicrobial assays \\ Determination of antimicrobial activity using Welldiffusion Method}

Antimicrobial activity was measured using a well diffusion method according to the National Committee for Clinical Laboratory Standard (NCLSI, 2011). Briefly, Petri plates containing approximately $25-30 \mathrm{ml}$ of Mueller Hinton agar medium were inoculated using a cotton swab with a 4-6 h old culture of the bacterial strains. Wells (10 $\mathrm{mm}$ diameter) were punched in the agar and filled with $100 \mu \mathrm{l}$ of tea extracts (green and black) and $25 \mu \mathrm{l}$ of penicillin $\mathrm{G}$ and gentamicin, respectively. Replicate of each plate was done in triplicates. The plates were incubated at $37^{\circ} \mathrm{C}$ for $18-24 \mathrm{~h}$. The antimicrobial activity $(\mathrm{mm})$ was assessed by measuring the inhibition zone diameters around the well. The average of three replicates for green and black tea extracts was calculated.

\section{Determination of the combined activity using Welldiffusion Method}

Combination of green tea extract with penicillin $\mathrm{G}$ and gentamicin was determined according to the National Committee for Clinical Laboratory Standard (NCLSI, 2011). A volume of $75 \mu \mathrm{l}$ of green tea extracts from a stock solution was combined with $25 \mu \mathrm{l}$ of penicillin $G$ and gentamicin that already been prepared from stock solution and added to each well. The plates were incubated at $37^{\circ} \mathrm{C}$ for $18-$ $24 \mathrm{~h}$. The average of three replicates for green tea extracts and in combination with antibiotics was calculated. Synergistic effect was considered when combinations of green tea extracts with penicillin $\mathrm{G}$ or gentamicin exhibited enlargement of combined inhibition zone diameter size by $0.5 \mathrm{~mm}$ (Ahmad and Aqil, 2007).

\section{Statistical analysis}

The results were presented in the form of tables and plates. The test was done in triplicates and the average and standard deviation results were computed using SAS statistical package 9.1 version.

\section{RESULTS}

\section{Antimicrobial activity for penicillin $\mathrm{G}$ and gentamicin}

Penicillin G showed the highest inhibition zone diameters 


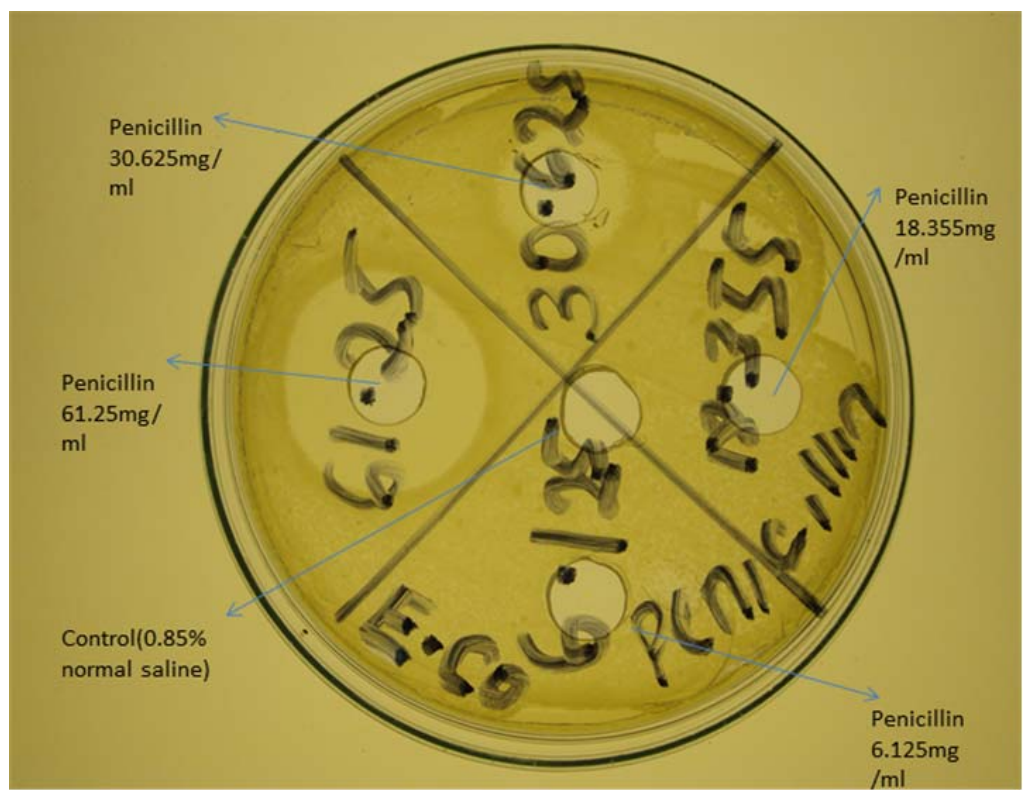

Figure 1. A representative image showing dose determination of penicillin $G$ on E. coli.

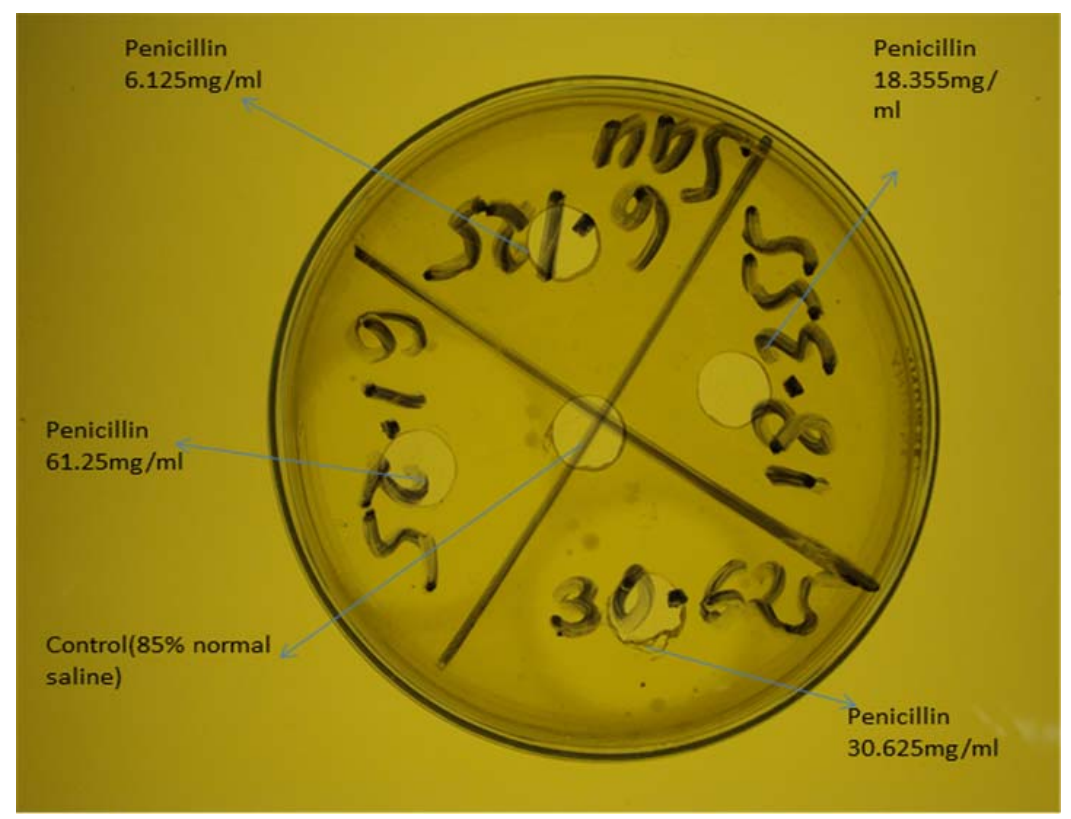

Figure 2. A representative image showing the dose determination of penicillin on $S$. aureus.

against both E. coli ATCC 25922 and S. aureus ATCC 25923 at high concentrations of $1.53 \mathrm{mg} / \mathrm{ml}$ (Figure 1) and $0.77 \mathrm{mg} / \mathrm{ml}$ (Figure 2). However, penicillin $\mathrm{G}$ at a lower concentrations of 0.46 and $0.15 \mathrm{mg} / \mathrm{ml}$ did not show any inhibition against E. coli ATCC 25922 and S. aureus ATCC 25923 (Table 1).

In addition, gentamicin inhibited E. coli ATCC 25922
(Figure 3) and S. aureus ATCC 25923 (Figure 4) but at lower concentration compared to penicillin $\mathrm{G}$. The highest inhibition zone diameter exhibited by gentamicin was at a concentration of $0.25 \mathrm{mg} / \mathrm{ml}$ (Table 1). Furthermore, lower concentrations of 0.13 and $0.08 \mathrm{mg} / \mathrm{ml}$ did inhibit $E$. coli ATCC 25922 and S. aureus ATCC 25923. However, gentamicin at a concentration of $0.03 \mathrm{mg} / \mathrm{ml}$ did not 
Table 1. Antimicrobial activity for penicillin $\mathrm{G}$ and gentamicin.

\begin{tabular}{lccc}
\hline \multirow{2}{*}{ Antibiotic } & $\begin{array}{c}\text { Concentration } \\
(\mathbf{m g} / \mathbf{m l})\end{array}$ & \multicolumn{2}{c}{ Inhibition zone diameters $(\mathbf{m m})$} \\
\cline { 3 - 4 } & 1.53 & $25.3 \pm 0.50$ & $37.3 \pm 0.58$ \\
\multirow{4}{*}{ Penicillin G } & 0.77 & $17.3 \pm 0.58$ & $26.5 \pm 0.50$ \\
& 0.46 & $0 \pm 0.00$ & $0 \pm 0.00$ \\
& 0.15 & $0 \pm 0.00$ & $0 \pm 0.00$ \\
& & & \\
\multirow{4}{*}{ Gentamicin } & 0.25 & $27.3 \pm 0.29$ & $26.2 \pm 0.29$ \\
& 0.13 & $25.7 \pm 0.58$ & $23.8 \pm 0.29$ \\
& 0.08 & $21.3 \pm 0.58$ & $22.7 \pm 0.58$ \\
\hline
\end{tabular}

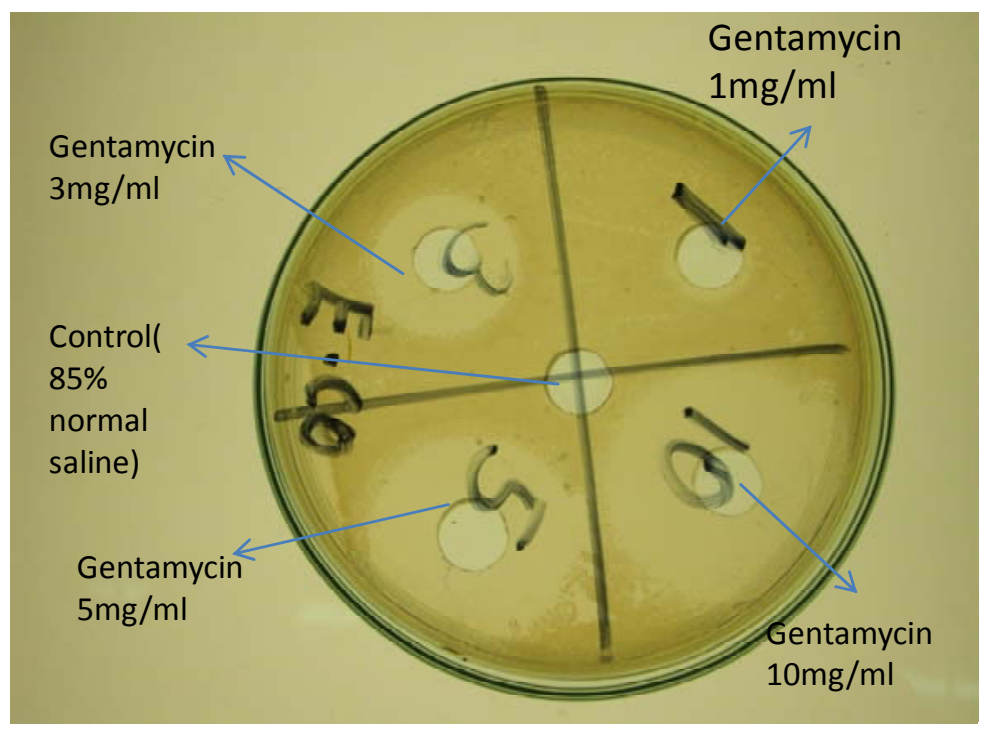

Figure 3. Results for antimicrobial activity for gentamicin in E. coli.

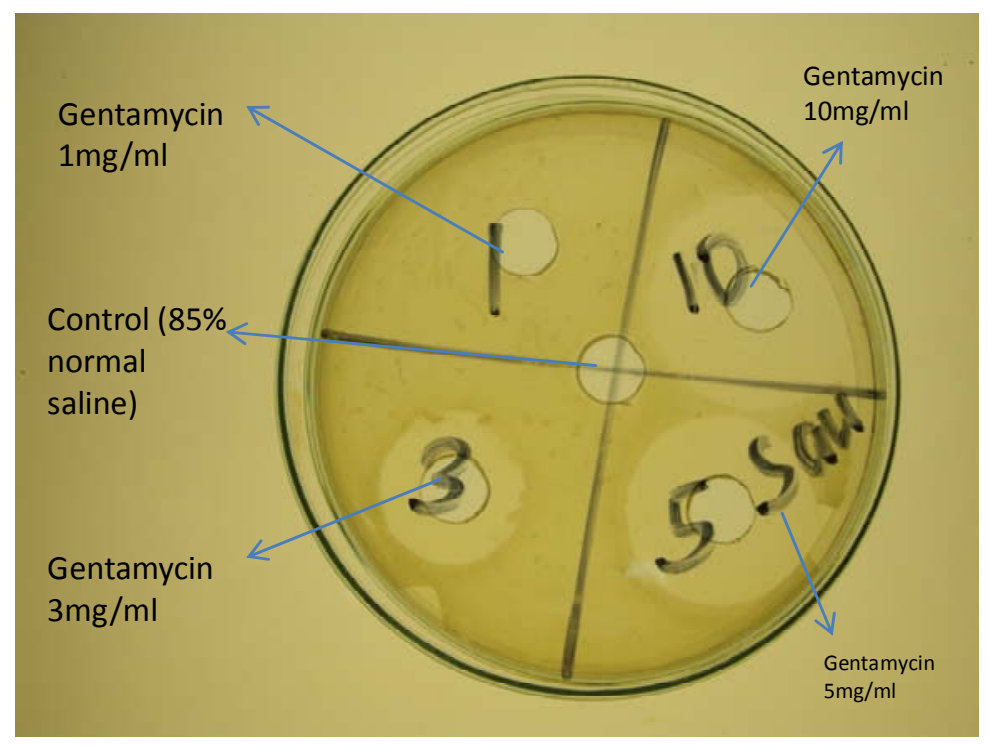

Figure 4. Results for antimicrobial activity for gentamicin in S. aureus. 
Table 2. Antimicrobial activity for green and black tea extracts.

\begin{tabular}{lccc}
\hline Tea sample & $\begin{array}{c}\text { Concentration } \\
(\mathbf{m g} / \mathbf{m l})\end{array}$ & \multicolumn{2}{c}{ Inhibition zone Diameters $(\mathrm{mm})$} \\
\cline { 3 - 4 } & 0.05 & E. coli ATCC 25922 & S. aureus ATCC 25923 \\
\hline Green tea & 0.10 & $0 \pm 0.00$ & $0 \pm 0.00$ \\
TRFK 6/8 & 0.20 & $21.3 \pm 0.29$ & $22.7 \pm 0.58$ \\
& 1.00 & $0 \pm 0.00$ & $0 \pm 0.00$ \\
& & $0 \pm 0.00$ & $0 \pm 0.00$ \\
Black tea & 0.05 & $27.3 \pm 0.58$ & $27.7 \pm 0.58$ \\
TRFK 6/8 & 0.10 & $0 \pm 0.00$ & $0 \pm 0.00$ \\
& 0.20 & $0 \pm 0.00$ & $0 \pm 0.00$ \\
& 1.00 & $0 \pm 0.00$ & $0 \pm 0.00$ \\
\hline
\end{tabular}

inhibit both E. coli ATCC 25922 and S. aureus ATCC 25923.

In this study therefore, both E. coli ATCC 25922 and S. aureus ATCC 25923 were more resistant to penicillin G as compared to gentamicin which exhibited high inhibition zone diameters at even lower concentrations (Table 1).

\section{Antimicrobial activity for green and black tea extracts}

The results on the antimicrobial activity of TRFK $6 / 8$ processed as green and black tea products are presented in Table 2. Green tea product processed from TRFK 6/8 exhibited an inhibition against both $E$. coli ATCC 25922 and S. aureus ATCC25923 at concentration of $0.1 \mathrm{mg} / \mathrm{ml}$. However, at alower concentration of 0.05 $\mathrm{mg} / \mathrm{ml}$, green tea extract did not exhibit any inhibition against the tested antibiotic resistant bacteria. Furthermore, on increasing the concentration of green tea extract, there was no inhibition against antibiotic resistant E. coli ATCC 25922 and S. aureus ATCC 26923. This could be attributed to the inability of higher concentration of tea extracts to diffuse through the Mueller Hinton agar medium.

Black tea extract processed from TRFK 6/8 tea cultivar exhibited different inhibitory effects compared to green tea processed from the same tea cultivar. Black tea extracts inhibited antibiotic resistant E. coli ATCC 25922 and S. aureus ATCC 25923 at lower concentration of $0.05 \mathrm{mg} / \mathrm{ml}$ compared to green tea of the same cultivar. However, increasing concentration of black tea extracts did not exhibit any inhibition observed earlier in green tea extracts. This may also be as a result of the inability of higher concentration of black tea extract to diffuse through the Mueller Hinton agar medium. From this study, black tea extract exhibited a higher inhibitory effect at lower concentration compared to green tea extracts. In addition, there was no significant difference in the inhibitory effects of black tea extract against antibiotic resistant E. coli ATCC 25922 and S. aureus ATCC 25923.

\section{Evaluation of green tea extracts interactions with some antibiotics}

In this study, green tea extract from the TRFK $6 / 8$ cultivar, exhibited an antagonistic effect against antibiotic resistant E. coli ATCC 25923 when combined with gentamicin (Figure 5). However, a combination of green tea extract with penicillin $\mathrm{G}$ exhibited a synergistic effect. Similar results were also observed when green tea extracts from TRFK 6/8 was combined with penicillin $G$ against antibiotic resistant S. aureus ATCC 25923 as shown in Figure 6. Green tea extracts in combination with gentamicin exhibited an additive effect against antibiotic resistant S. aureus ATCC 25923. In addition, it was also observed that the green tea extract from TRFK 6/8 cultivar exhibited a higher inhibition zone diameters as compared to penicillin $\mathrm{G}$ and its activity was comparable to that of gentamicin (Table 3 ).

\section{DISCUSSION}

Tea is one of the most popular non-alcoholic beverages with health enhancing effects. The inhibitory effect of green and black tea extracts on antibiotic resistant bacteria has been reported (Bandyopadhyayet et al., 2005). The results of the present study show that green tea and black tea processed from TRFK 6/8 have antimicrobial activity on antibiotic resistant $E$. coli ATCC 25922 and S. aureus ATCC 25923. These results are in agreement with the finding of Koech et al. (2013b). Although black and green tea both contain similar amount of flavonoids, their chemical structure is different. Green tea contains more catechins (simple flavonoids) but during black tea processing, leaf oxidation converts these simple flavonoids to more complex theaflavins and thearubigins (Cabrera et al., 2006). These catechins, theaflavins and thearubigins are the antimicrobial agents present in tea (Hamilton-Miller, 1995; Luczaj and Skrzydlewska, 2005).

The findings in this study also indicated that the 


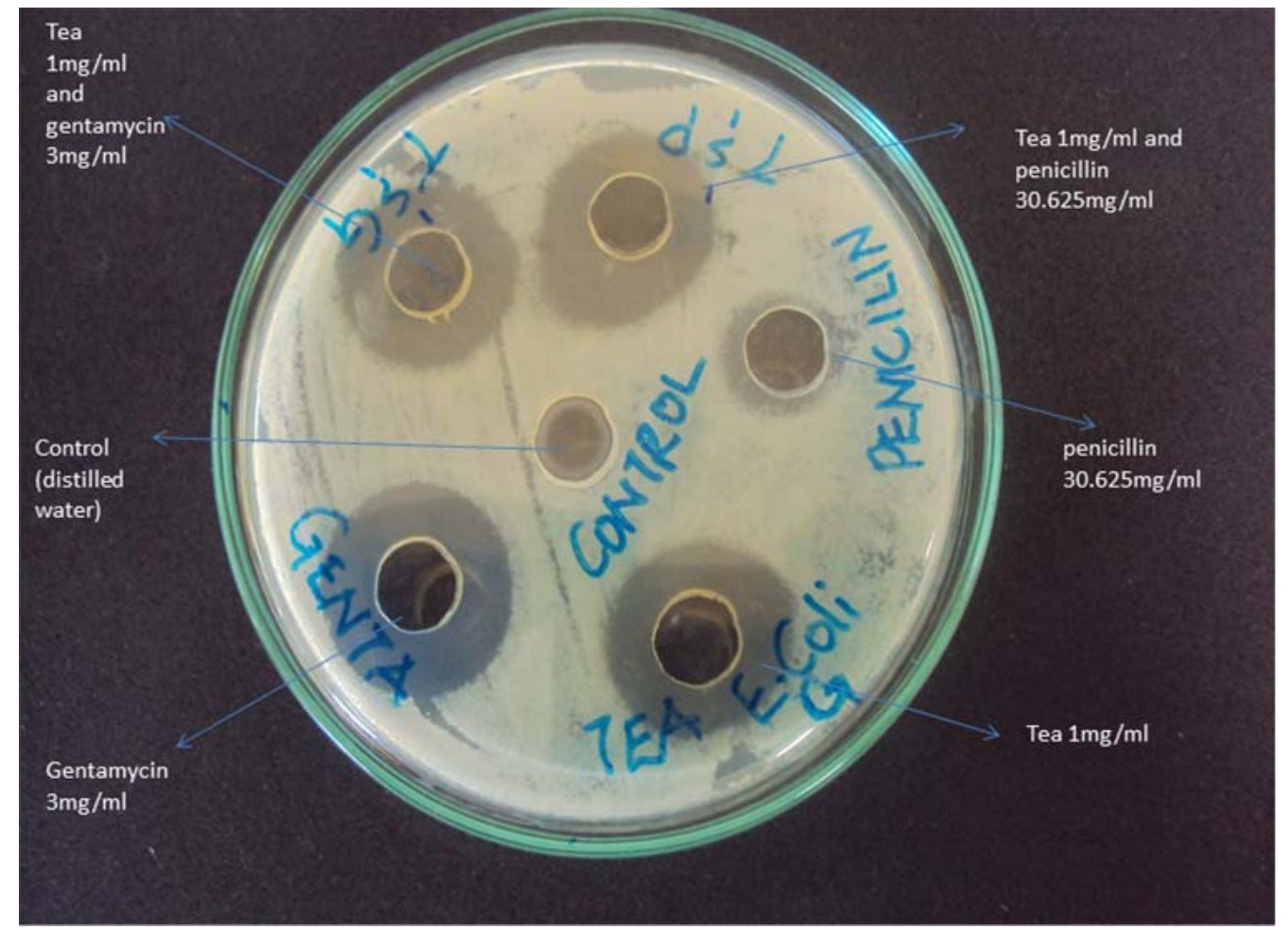

Figure 5. Antibacterial and synergistic activity of water soluble tea extracts with antibiotics against $E$. coliATCC 25922 and S. aureusATCC 25923. TP- tea and penicillin, TG- tea and gentamicin, GENTA- gentamicin.

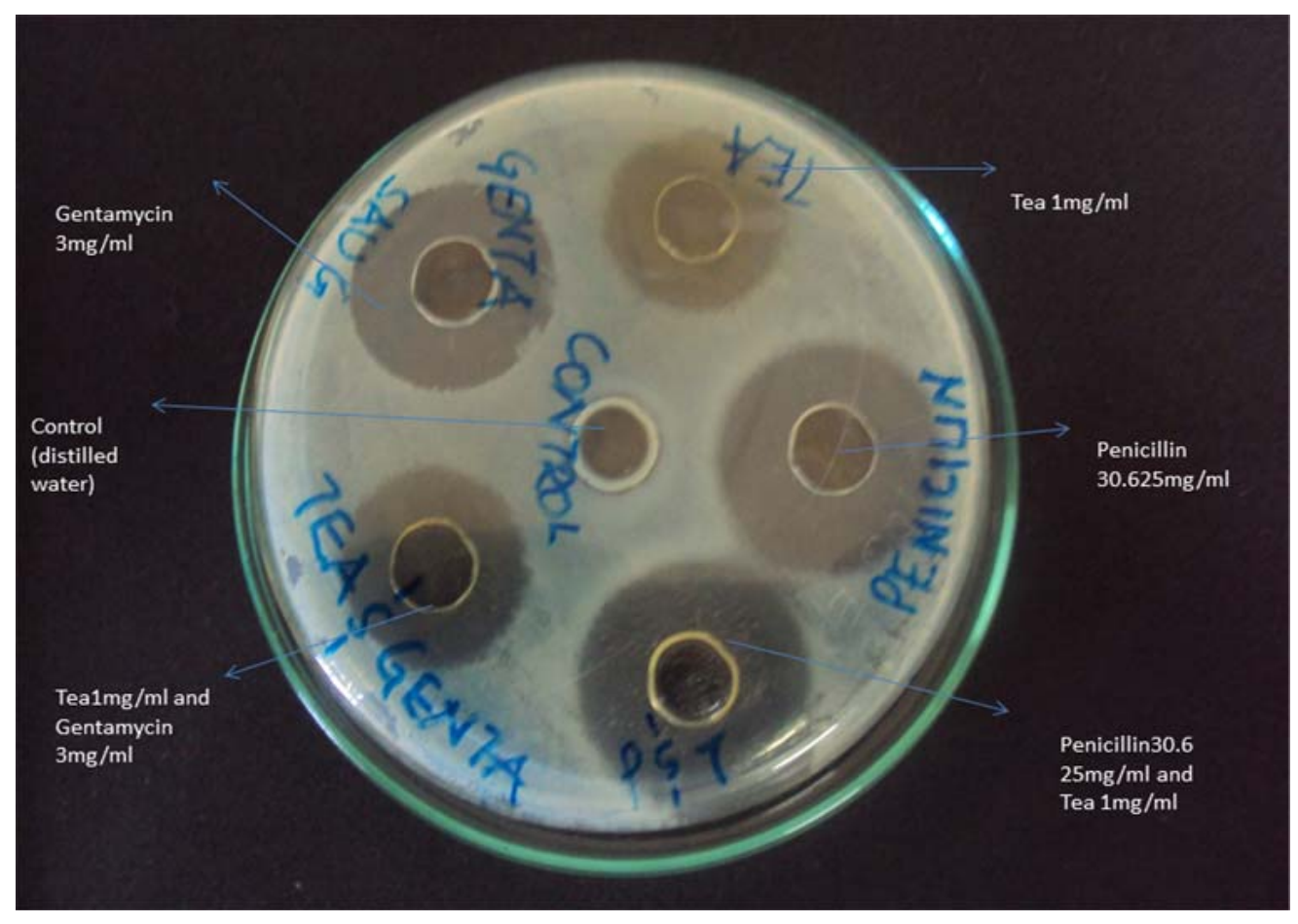

Figure 6. Antibacterial and synergistic activity of water soluble tea extracts with antibiotics against E. coliATCC 25922 and S. aureusATCC 25923. TP- tea and penicillin, TG- tea and gentamicin, GENTA-gentamicin. 
Table 3. Evaluation of green tea extracts interactions with some antibiotics.

\begin{tabular}{lccccc}
\hline Tested bacteria & $\begin{array}{c}\text { Gentamicin } \\
\mathbf{( 0 . 0 8} \mathbf{~ m g} / \mathbf{m l})\end{array}$ & $\begin{array}{c}\text { Penicillin G } \\
\mathbf{( 0 . 7 7} \mathbf{~ m g} / \mathbf{m l})\end{array}$ & $\begin{array}{c}\text { Tea }(\text { Green) } \\
(\mathbf{0 . 1} \mathbf{~ m g} / \mathbf{m l})\end{array}$ & $\begin{array}{c}\text { Tea + Gentamicin } \\
(\mathbf{0 . 1}+\mathbf{0 . 0 8} \mathbf{~ m g} / \mathbf{m l})\end{array}$ & $\begin{array}{c}\text { Tea + Penicillin G } \\
(\mathbf{0 . 1}+\mathbf{0 . 7 7} \mathbf{~ m g} / \mathbf{m l})\end{array}$ \\
\hline E. coli ATCC 25922 & $22.3 \pm 0.50$ & $18.5 \pm 0.58$ & $21.3 \pm 0.33$ & $19.2 \pm 0.33$ & $25.3 \pm 0.50$ \\
S. aureuS ATCC 25923 & $23.2 \pm 0.28$ & $27.3 \pm 0.28$ & $23.7 \pm 0.33$ & $23.2 \pm 0.29$ & $28.7 \pm 0.29$ \\
\hline
\end{tabular}

antimicrobial effects of assayed tea extracts differed depending on the type and the concentration of the tea extract and also the type of test organism. The inhibitory effect of black tea extract on E. coli ATCC 25922 and S. aureus ATCC 25923 was lower in concentrations than green tea extract. This finding is in agreement with the previous studies in which black tea extracts exhibited high antimicrobial activity against Streptococcus mutans more than green tea extracts (Hamdi et al., 2008).

In this study, increasing concentration of tea extracts (green and black) resulted in no inhibition activity. This could be attributed to the inability of higher concentrations of the tea extract to diffuse through the Muller Hinton agar medium. This impairment in drug diffusion is a major limitation in the evaluation of the antimicrobial effects of plant extracts using agar diffusion method (Esiome et al., 2006). The conclusion by Taguri et al. (2006) that the antimicrobial potency of tea polyphenols is dependent upon bacterial species is consistent with the findings of this study, which showed that, the green and black tea extracts were more active against the Grampositive, S. aureus ATCC 25923 as compared to E. coli ATCC 25923 which is Gram-negative.

The antimicrobial results of this study showed a marked increase in the inhibition zone diameters on combination of green tea extracts with penicillin $G$. This is in agreement with results by (Hu et al., 2002) who reported enhanced effect of tea extracts on inhibitory activities with $\beta$-lactams antibiotics against antibiotic resistant $S$. aureusATCC 25923 . Synergistic inhibition by green tea extracts and penicillin $G$ could be attributed to the presence of dual binding sites on the bacterial surface for antibiotic and tea extract (Tiwari et al., 2005). The tea extracts-induced damage of the bacterial cell wall and the possible interference with its biosynthesis through direct binding with peptidoglycan may be the major reasons for the synergism against antibiotic resistant $S$. aureusATCC 25923. When green tea extract was combined with gentamicin against $S$. aureus ATCC 25923, an additive effects was observed which could be hypothesized that gentamicin also directly or indirectly attacks the same site. The double attack of both agents on different target sites of the bacteria could theoretically lead to an additive effect (Esiome et al., 2006). However, antagonistic interaction between green tea extracts and gentamicin was observed against E. coli ATCC 25922. This could be because green tea extract and gentamicin have different mode of action against tested bacteria.

\section{Conclusion}

In conclusion, green and black tea exhibited antimicrobial properties against antibiotic resistant E. coli ATCC 25922 and S. aureus ATCC 25923. In addition, green tea extracts did not impair the antimicrobial properties of penicillin $G$ but rather it enhanced its activity in synergistic manner. The combination of green tea extract and penicillin $G$ could be useful in management of emerging antibiotic resistant bacteria.

\section{ACKNOWLEDGMENTS}

We thank the Division of Research and Extension of Egerton University for funding this project. We also thank the Tea Research Foundation of Kenya for the facilitation and technical expertise.

\section{Conflict of Interests}

The author(s) have not declared any conflict of interests.

\section{REFERENCES}

Ahmad I, Aqil F (2007).In vitro efficacy of bioactive extracts of 15 Medicinal plants against ESL-producing multidrug-resistant enteric bacteria. Microbiol. Res. 162: 264-275.

Bandyopadhyayet D, Chatterjee TK, Dasgupta A, Lourduraja J, Dastidar SG (2005). In vitro and in vivo antimicrobial action of tea: The commonest beverage of Asia. Biol. Pharm. Bull. 28: 2125-2127.

Bastos DM, Ishimoto EY, Marcia UM, Ferri AF, Torres EA.(2006). Essential oil and antioxidant activity of green mate tea (Ilex paraguariensis) infusions. J. Food Comp. Anal. 19: 538-543.

Cabrera C, Artacho R, Gimenez R (2006). Beneficial effects of green tea-a review. J. Am. Coll. Nutr. 25 (2):79-99.

Cabrera C, Gimenez ME, Lopez CM (2003). Determination of tea components with antioxidant activity. J. Agric. Food Chem. 51: 44274435.

Das DN (1962). Studies on antibiotic activity of tea.J. Indian Chem. Soc. 39: 849-854.

Esiome CO, Iroha IR, Ibezim EC, Okeh CO, Okpana EM (2006).In vitro evaluation of the interaction between tea extracts and penicillin $G$ against Staphylococcus aureus. Afr. J. Biotechnol. 5: 1082-1086.

Friedman M, Henika PR, Levin CE, Mandrell RE, Kozukue N (2006). Antimicrobial activities of tea catechins and theaflavins and tea extracts against Bacillus cereus. J. Food Prot. 69: 354-361.

Gallaher RN, Gallaher K, Marshall AJ, Marshall AC (2006). Mineral analysis of ten types of commercially available tea. J. Food Comp. Anal.19: 53-57.

Hamdi K, ShoaHasani AR, Ordouzadeh N, Ghaemi A (2008). The effect of black and green tea extracts on dental-plaque forming Streptococci. Shahrekord Univ. Med. Sci J. Fall. 10(3): 1-8. 
Hamilton-Miller JM (1995). Antimicrobial properties of tea (Camellia sinensis L.). Antimicrob. Agents Chemother. 39: 2375- 2377.

Hiroshi Y (2012). Tea Catechins and Staphylococcus aureus. In: Preedy (eds) Tea in health and disease prevention. Elsevier, London, pp. 1207-1213.

Hu ZQ, Zhao WH, Asano N, Yoda Y, Hara Y, Shimamura T (2002). Epigallocatechingallate synergistically enhances the activity of carbapenems against methicillin- resistant Staphylocccusaureus. Antimicrob. Agents Chemother. 46: 558-560.

Hu ZQ, Zhao WH, Shimamura T (2004). Different susceptibilities of Staphylococcusand gram negative rods to EGCG: In Proceedings of International Conference of Tea Culture and Science. Shizuoka Japan. pp. $578-581$.

Karori SM, Wachira FN, Wanyoko JK, Ngure RM (2007). Antioxidant capacity of different types of tea products. Afr. J. Biotechnol. 6: 22872296.

Koech KR, Wachira FN, Ngure RM, Wanyoko JK, Bii C, Karori SM (2013b). Antibacterial and synergistic activity of different tea crude extracts against antibiotic resistant $S$. aureus, E. coli and a clinical isolate of S. typhi. Sci. J. Microbiol. 3: 2276-626X

Lu H, Meng X, Li C, Sang S, Patten C, Sheng S, Hung J, Bai N, Winnik B, Ho TC, Yang CS (2003).Glucoronides of tea catechins: Enzymology of biosynthesis and biological activities. Drug Metab. Dispos. 31:452-461.

Luczaj W, Skrzydlewska E (2005). Antioxidative properties of black tea. Prev. Med. 40: 910-918.

National Clinical and Laboratory Standards Institute (NCLSI) (2011).M100-S21, Performance standards for antimicrobial susceptibility testing; Twenty-First informational supplement Wayne, PA.
Obanda M, Owuor PO, Mang'oka R (2001). Changes in the chemical and sensory quality parameters of black tea due to variations of fermentation time and temperature. J. Food Chem. 75: 395-404.

Osterburg AR, Karen LM, George FB (2012). AntibacterialAcinetobacter baumannii- Activity of Epigallocatechin-3-Gallate (EGCG) In: Preedy (eds). Tea in health and disease prevention. Elsevier, London, pp. 1195-1206.

Taguri T, Tanaka T, Kouno I (2006). Antibacterial spectrum of plant polyphenols and extracts depending upon hydroxyphenyl structure. Biol. Pharm. Bull. 29: 2226-2235.

Tiwari RP, Bharti SK, Kaur RP, Dikshit RP, Hoondal GS (2005). Synergistic antimicrobial activity of tea and antibiotics. Indian J. Med. Res.122: 80-84.

Vanessa C, Williamson $G$ (2004). A review of the health effects of green tea catechins in in-vivo animal models. J. Nutr. 134: 3431-3440.

Yamamoto MM, Inagaki N, Kitaura J, Chikumoto T, Kawahara H, Kawakami Y, Kawakami T, Nagai H (2004). O-Methylated catechins from tea leaves inhibit multiple protein kinases in mast cells. J. Immunol. 172: 4486-4492. 